\title{
Effect of vehicular loading on suspension bridge dynamic properties
}

\author{
Robert Westgate $^{\mathrm{a}}, \mathrm{Ki}^{-}$Young Koo ${ }^{\mathrm{b}} \&$ James Brownjohn*c \\ ${ }^{a}$ Department of Civil and Structural Engineering, University of Sheffield, Sheffield, \\ United Kingdom; ${ }^{b}$ Department of Civil Engineering, Kyungil University, Daegu, \\ Republic of Korea, ${ }^{c}$ College of Engineering, Mathematics and Physical Sciences, \\ University of Exeter, United Kingdom
}

Corresponding author. Email: j.brownjohn@exeter.ac.uk

Correspondence details: University of Exeter, North Park Road, Exeter EX4 4QF, +44 01392723698 


\section{Effect of vehicular loading on suspension bridge dynamic properties}

Since the 1970s many researchers have attempted to use changes in natural frequencies as means for condition assessment of large civil engineering structures such as bridges, but have faced the challenge of decoupling frequency variations apparently caused by changing operational conditions. In the case of the Tamar Bridge in southwest England, time series of natural frequencies exhibit diurnal variations resulting from a combination of thermal and vehicular loading, whose effects would need to be compensated for in dynamics-based assessment. By examination of several years of monitoring data, the effects of traffic mass have been characterised and compared with other operational effects. While temperature changes appear to have a greater influence for lateral modes, traffic mass is a strong factor in all modes and the dominant factor for the vertical and torsional modes evaluated.

Physics-based explanations for the variable effects of vehicle mass have been sought using a finite element model calibrated against experimental data. As a caution for performance prediction in structural dynamics, while acceptable reconciliation of natural frequencies from FE model and measurements was achievable, reconciling simulated effects of changing mass with observed behaviour has not been straightforward due to the complexity of the retrofitted suspension bridge structure studied.

Keywords: bridges, long-span; bridges, suspension; cables; damage assessment; finite element method; roads \& highways; structural dynamics; structural engineering; suspended structures; traffic engineering. 


\section{Introduction: variations in bridge loading and dynamic response characteristics}

Structural Health Monitoring (SHM) implementations on civil infrastructure (Brownjohn, 2007) have many purposes that include the tracking of time varying loads and responses in order to identify, characterise and diagnose anomalous performance. In particular, changes in dynamic response parameters, e.g. modal properties such as natural frequencies, have been regarded by many researchers as a possible indicator of structural 'damage' (Brownjohn et al., 2011). SHM systems may also be used to validate design assumptions, for example regarding thermal and vehicular loads. Hence there are strong motives for studying time series of structural loads (wind, vehicles and temperature) and dynamic response parameters and their relationships.

For long span bridges in particular wind-structure interaction can result in modification of modal parameters and lead to catastrophic instability due to the phenomenon of aero-elasticity (Wyatt, 1992). Such effects can be observed not only in wind tunnel testing but also at full scale, using SHM systems (Diana at al., 1992) and there is a large body of research on the topic.

Rather fewer studies have examined the link between thermal loads (diurnal and seasonal temperature variations) and dynamic properties, which are reviewed by Xia, Chen, Weng, Ni and Xu (2012). Of these only a few studies have reported such links in suspension bridges (Oh et al., 2009; Miao et al., 2011; Ding \& Li, 2011).

There are other environmental and operational loads that also feature diurnal and seasonal variations, in particular traffic. As well as directly affecting vibration levels, vehicles alter mass properties while imposing static loads that result in deck deflections and (in a suspension bridge) cable tension changes. This particular effect on dynamic properties has been reported in several experimental works. During a series of ambient 
vibration tests on a highway bridge Farrar and James III (1997) observed higher modal frequencies as well as lower modal damping ratios during tests when no traffic was present. During a 24-hour dynamic test of a cable-stayed bridge during conditions of calm wind and minimal ambient temperature variation Zhang et al. (2002) found variations of approximately $1 \%$ for the natural frequencies. Magalhães et al. (2012) observed both temperature and traffic dependent variations from long term monitoring of a $280 \mathrm{~m}$ long concrete arch bridge, in particular they found pronounced drops in frequencies during morning rush hours.

The suspension bridge that is the subject of this paper and that has been monitored for several years is marginally wind-sensitive, but exhibits striking diurnal variations in lower mode natural frequencies. The character of these variations led to an initial hypothesis that temperature variation was the root cause. It has been a kind of detective work to determine what type of load actually drives the frequency variations and why, but in this paper the physics based explanation has been limited to the vehicle load effect. The response caused by the temperature of the structure is reported separately due to the complexity of the thermal investigation. It turns out that while temperature does have the stronger influence for one or two modes, the added mass due to vehicle traffic has the stronger effect for most modes, depending on the type of mode.

\section{Tamar Bridge monitoring system and finite element model}

\section{Bridge details}

Tamar Bridge was opened in 1961, and links the towns of Plymouth and Saltash on east and west sides of the River Tamar in South West England. The $335 \mathrm{~m}$ main span is suspended halfway up the $73.2 \mathrm{~m}$ tall concrete towers, which are seated on caisson foundations. The supporting structure of the deck is a $4.9 \mathrm{~m}$ deep steel truss, and the 
steel suspension cables are $38 \mathrm{~cm}$ in diameter. As part of a strengthening and widening exercise completed in 2001, a steel orthotropic deck replaced the previous composite deck and two $6 \mathrm{~m}$ wide lanes were cantilevered either side of the truss, increasing the width to $27.2 \mathrm{~m}$. The bridge now has three traffic lanes on the orthotropic deck, one eastbound traffic lane on the northern cantilever of the bridge and a pedestrian and cycle path on the southern cantilever. Since 1961 truss sag had increased and was brought back to the original profile by adding eight pairs of additional stay cables were installed, whose layout is shown in Figure 1, while the present truss and deck arrangement is shown in Figure 2. As well as the eight pairs $(\mathrm{S} 3, \mathrm{~S} 1, \ldots, \mathrm{P} 3)$ that connect the Saltash or Plymouth main towers to either the truss or the base of the side towers, an extra pair ("5") are attached to the lower chords of the truss. The original mass of the deck $\left(7900 \times 10^{3} \mathrm{~kg}\right)$ was increased only by $25 \times 10^{3} \mathrm{~kg}$ through removal of the old deck $\left(2800 \times 10^{3} \mathrm{~kg}\right)$, addition of the new orthotropic deck and cantilevers $\left(2800 \times 10^{3} \mathrm{~kg}\right)$ and installation of the stay cables $\left(125 \times 10^{3} \mathrm{~kg}\right)$.

Thermal expansion of the bridge deck is accommodated by an expansion gap located near the main tower on the Saltash side. The joints in the bridge that allow for the movement are thrust bearings at the towers which restrain lateral sway of the bridge, and a pair of pendel bearings at each end of the truss providing some vertical restraint at the ends of the spans.

\section{Monitoring system}

Alongside the strengthening and widening exercise a structural monitoring system was installed to provide an overview of vertical plane configuration of the bridge and stay cable tensions during the upgrade and subsequently in service. It also provides the operator with site meteorological data and since 2006 has provided data for the present 
monitoring exercise. The location of the sensors on the bridge that make up the system are shown in Figure 1.

There are ten thermogauges attached to the structure: six at the mid-span for measuring the deck and truss temperature, one on the northern suspension cable at midspan, one on each side span for deck temperature, and one on a hanger near the Saltash tower to measure air temperature. Anemometers are located on the main towers and on the side spans to gauge the wind speed and direction near the bridge. Further details on the monitoring system are provided by Koo et al. (2012).

The sensors which are particularly important for the study in this paper are the uni-axial servo-accelerometers strategically located near the centre of the main span: two measuring vertical accelerations, and a third measuring the lateral acceleration. The accelerometer signals are sampled at $64 \mathrm{~Hz}$, while the temperature, weather and tension signals are sampled at $0.1 \mathrm{~Hz}$ and summarised as half-hourly averages.

\section{Experimental modal analysis and automatic identification of modal frequencies using the Stochastic Subspace Identification (SSI) procedure}

A modal survey during daylight hours of $28^{\text {th }}$ April 2006 (Brownjohn et al., 2007) provided a snapshot of the modal parameters over one day of bridge operation. Sixteen accelerometers allowed the modes to be mapped out so that individual frequencies could be associated with specific modes during subsequent monitoring. Four of the accelerometers remained at the same reference locations, while twelve "roving" accelerometers were repositioned over the structure after every measurement, which would last up to half an hour. The first two vertical, first two lateral and first torsional modes of the suspended structure were identified for tracking, and an optimal location was chosen for the three accelerometers permanently installed in late 2006. 
Modal properties are calculated from the accelerations automatically using the data-driven stochastic subspace identification (SSI) method (Van Overschee \& De Moor, 1996; Peeters \& De Roeck, 1999). Beginning with accelerometer installation, the procedure was implemented in the acquisition software that sent daily email summaries of modal parameters. The system was later revised to process data on a central server that can be accessed by web viewer and MATLAB functions for inspection and further analysis of bridge performance trends. The SSI procedure produces frequency and damping estimates for the first few modes in vertical and horizontal directions from successive 30-minutes acceleration time series, i.e. 48 samples per mode per day.

\section{Time series and patterns in temperature and temperature loads}

\section{Temperature variation}

Structural and air temperature data are readily available as 30 minute averages without further processing. Figure 3 shows four days of temperature values for the main cable, the truss and deck as well as for air. Determining a representative temperature value for structural effects from any one temperature channel or from a weighted combination is not a simple problem, since different responses would be driven by different temperature representations. Since main cable tension has a significant influence on natural frequencies for lower modes it is natural to consider main cable temperature as a possible proxy for thermal effects on natural frequencies.

\section{Traffic volume and vehicle characteristics}

Tamar Bridge has a weigh-in-motion (WIM) system but it has not been operational for several years, so there is no direct method to quantify vehicle masses and hence estimate the mass of vehicles on the structure at a given time. Hence the only remaining 
option is to count vehicles and estimate mass according to their classification. The obvious source is toll data, which group hourly-sampled counts for vehicles travelling from Saltash to Plymouth into one of ten possible classes as presented in Table 1. The classes go by axle configurations, with average gross mass determined by the British Department for Transport (2008). Four of these classes (06, 07, 08 and 09) include trailers, and since they represent a small percentage of the bridge traffic the number of classes can be reduced to six. Almost $93 \%$ of the vehicles using the bridge are classed as a car or a van (CLASS02), with vans having nearly double the average gross mass of a car. In order to determine a reasonable mass for a typical CLASS02 vehicle it was assumed that British cars make up 404.1 billion kilometres of road usage, while vans use 68.2 billion kilometres (Department for Transport, 2008). This would mean that nearly $86 \%$ of the vehicles in this class are cars, leading to the average CLASS02 vehicle mass as a weighted combination of cars and double-cars (vans). Likewise the mass of heavy goods vehicles (HGVs) is obtained by scaling toll counts with average weight according to classification.

Figure 4 presents averages for the Plymouth-bound hourly traffic mass arranged in 24 one-hour bins, for samples collected during weekdays and at the weekend respectively. Cars provide the majority of the traffic mass, with four axle HGVs also providing a significant portion of the remaining total. The trapezoidal profile in both graphs forms a plateau between 07:00 and 17:00, and a distinct peak at 08:00 caused by rush-hour commuters (eastbound into Plymouth). The lowest vehicle counts occur between 02:00 and 04:00. There are seasonal variations, for example fewer cars over the Christmas/New Year period and more during summer months (due to holiday traffic to/from Cornwall).

The traffic mass for records collected at the weekend have a different hourly 
profile compared to records collected on weekdays. There is reduced HGV traffic at weekends and there is no pronounced peak at 08:00, rather a shallower rise and fall, peaking at 11:00. The mass of vehicles is reduced by approximately one third.

Since the toll data cover only the eastbound direction there is no method for estimating hourly totals with a level of accuracy corresponding to the one-way toll data and an approximation is required if any progress is to be made. There are two possible approaches, which are demonstrated in Figure 5; one would be to double the toll counts, the other would be to flip the toll data between the morning and afternoon peaks then add the result. Flipping the data results in daily time series profiles that are symmetric about a time chosen around midday.

The doubling option is supported by bi-directional toll data from New York bridges (Sadik-Khan, 2012). These show that in most cases bridge traffic entering the city features the concentrated morning peak while afternoon traffic is more spread out over a longer period, e.g. due to child collection from school and other after-work activities. Finally, bi-directional vehicle counts and masses were estimated from two days of slow-sampled webcam data, which also support the doubling up option.

\section{Traffic mass}

Hourly toll values were taken as representing vehicle counts in the hour following the toll value time stamp, and were then interpolated and mass-weighted, with appropriate time shifts to provide half-hourly mass values corresponding to the 30 -minute frequency estimation time window. Assuming vehicles take 42 seconds to cross the $563 \mathrm{~m}$ span driving at the UK $13.4 \mathrm{~m} /$ second (30 mile per hour) speed limit the average number of vehicles on the bridge is approximately $1 / 43$ rd of the half-hourly count. After doubling the values to approximate the non-tolled direction, the resulting estimate was found to 
match the sample webcam vehicle counts to within a few $\%$.

The result is shown in Figure 6. There are of course instances when the bridge is empty and when it is full of vehicles, but since both the traffic and modal properties of the bridge are being handled in 30 minute averaging periods the instantaneous mean is a reasonable representation.

\section{Time series and patterns in modal frequencies}

Table 2 summarises natural frequencies and their statistical distributions based on the 6 years of monitoring from the end of 2006. All but one of the observed frequencies have a coefficient of variation (COV) less than $1 \%$, while that for the first lateral mode (LS1a) is more than twice this range. The skew of the frequencies for most of the modes is negative, due to the long tails in the frequency distributions below the mean.

While some of the variation could be attributed to random error in the system identification process ( $\mathrm{Au}, 2012)$, there are clear diurnal patterns in the frequency time series, a four-day sample of which is shown in Figure 7. In all five of the observed modes shown there are frequency drops during the day, but the clearest variations are in the lowest three modes. The large variation for the first lateral mode, LS1a, which is about $10 \%$ of its mean value, is clearly visible.

While the COV values are low, the challenge for vibration-based diagnostic techniques is to discriminate signals representing these changes from the combination of random identification error and the changes due to varying environmental and operational loading conditions (Sohn, 2007). 


\section{Periodicity in natural frequency time series}

In order to mitigate the effect of random error in the identification, frequencies for the first three modes are presented in Figures 8 to 10 as superimpositions of 31 days of modal frequencies values from June 2009, rearranged by the hour of measurement. On close inspection the frequency time series for modes such as VS1 and VA1 (Figure 8 and Figure 10) form trapezoidal profiles with plateaus between 08:00 and 17:00 and peaks twice daily; a mirror with the hourly traffic levels (in Figure 4). On the other hand for LS1a (Figure 9) the trend of rounded curves resembles the temperature variation shown in Figure 3. While both temperature and traffic may be factors in each case, it seems that some modes may be much more susceptible to traffic effects than to structural temperatures, and vice-versa. Additionally the behaviour of frequency data collected during the weekend is markedly different from data during weekdays; the time series profiles appear more rounded for all three modes shown.

More sophisticated analysis is required to interpret and diagnose the trends, beginning with characterisation of periodicity then moving to curve-fitting among traffic, temperature and frequency time series. Strong wind events that might slightly affect modal properties are rare and random and may only contribute to a few of the outliers in the plots of Figures 8 to 10 .

Since the data have been separated into groups for weekday and weekend performance the time intervals are uneven, and the discrete Fourier transform cannot be used. Hence the Lomb-Scargle periodogram is used, which is designed for unevenly spaced signals (Pytharouli \& Stiros, 2008).

The procedure for identifying the spectral power for each sampling frequency of interest $f_{s}$ is as follows: Given a set of data values $x=\left[\begin{array}{lll}x_{1} & \mathrm{~L} & x_{N}\end{array}\right]^{T}$ and 
corresponding occurrence times $\stackrel{I}{t}=\left[\begin{array}{lll}t_{1} & \mathrm{~L} & t_{N}\end{array}\right]^{T}$, the mean $(\mu)$ and variance $\left(\sigma^{2}\right)$ of the data in $\vec{x}$ is first identified, and a circular frequency is determined for each sampling frequency of interest $\left(\omega_{s}=2 \pi f_{s}\right)$. Consequently, a constant time offset for each sampled frequency $\hat{t}_{s}$ is computed by

$$
\tan \left(2 \omega_{s} \hat{t}_{s}\right)=\frac{\sum_{i=1}^{N} \sin \left(2 \omega_{s} t_{i}\right)}{\sum_{i=1}^{N} \cos \left(2 \omega_{s} t_{i}\right)}
$$

Then the spectral power $p$ for each value of $\omega_{s}$ is defined by Equation 2:

$$
p\left(\omega_{s}\right) \equiv \frac{1}{2 \sigma^{2}}\left\{\frac{\left(\sum_{i=1}^{N}\left(x_{i}-\mu\right) \cos \left(\omega_{s} t_{i}-\omega_{s} \hat{t}_{s}\right)\right)^{2}}{\sum_{i=1}^{N} \cos ^{2}\left(\omega_{s} t_{i}-\omega_{s} \hat{t}_{s}\right)}+\frac{\left(\sum_{i=1}^{N}\left(x_{i}-\mu\right) \sin \left(\omega_{s} t_{i}-\omega_{s} \hat{t}_{s}\right)\right)^{2}}{\sum_{i=1}^{N} \sin ^{2}\left(\omega_{s} t_{i}-\omega_{s} \hat{t}_{s}\right)}\right\}
$$

Finally, periodicities in the observed data can be distinguished by arranging the spectral powers and the sampling frequencies in a Lomb-Scargle periodogram.

The application of the constant $\hat{t}_{s}$ makes Equation 2 identical to the equation one would obtain if estimating the harmonic content of a data set at a given circular frequency $\omega_{s}$ via linear least-squares fitting to the model $x(t)=A \cos \left(\omega_{s} t\right)+B \sin \left(\omega_{s} t\right)$. While computationally intensive, since the method weights data on a point-by-point basis (rather than time-by-time as in a Fourier transform), it is advantageous for applications with unevenly spaced data. The spectral power is reweighted by the variance of the observed data, so the values should not be used to measure the amplitude of the fluctuating data, but may be used to identify the most significant periodicities.

The periodograms presented in Figures 11 to 13 correspond to the data of Figures 8 to 10 and show the periodic behaviour of the first three frequencies, 
suggesting the presence of harmonics in the data. The largest peak in each periodogram indicates a frequency of exactly once per day, like the diurnal temperature and traffic variations. The smaller neighbouring peaks (around 0.85 and 1.15 per day) merely show that the response data are not perfectly periodic.

Additionally the VS1 data contain second and third order harmonics which represent the departure from a perfectly sinusoidal character. These harmonics are attributable to the troughs forming between 06:00 and 09:00 in the time series of the natural frequencies, suggesting a link to the higher levels of traffic that occur during the morning rush hour. The second and third harmonics are barely visible for LS1a and VA1, compared to VS1 suggesting that traffic has a lesser influence on these modes.

\section{Relating frequency variation to temperature and traffic mass variations}

As seen previously in the profiles of the time series (Figures 8 to 10), while VS1 has peaks in frequency at rush hour, LS1a has a curved profile that more closely resembles the diurnal temperature profiles. Also the frequency analysis shows only weak harmonics except for VS1 during weekdays, suggesting that the smoother variations in temperature dominate.

An indication of the variation of the frequencies with temperature excluding the effect of traffic can be obtained using frequency and temperature data recorded daily at 4AM, when traffic levels are at similar very low levels throughout the year. Figure 14 shows that all five frequencies have an inverse relationship with suspension cable temperature, with mode LS1a being strongly affected.

The relative sensitivities of bridge modal frequencies to temperature and mass effects have been more systematically investigated using the polynomial response surface models, as adopted by Cross et al. (2013). Like other regression methods, their 
main advantage is their simplicity due to use of the least squares method, with the generated coefficients aiding physical interpretation of the data.

To avoid complicating the interpretation, the fit was limited to a small number of possible variables. Moreover the monitored frequencies were limited to samples of 5 miles per hour $(2.24 \mathrm{~m} / \mathrm{s})$ wind speeds and below, to remove any likelihood of the wind affecting the dynamic results. For simplicity the response surface model adopted in the analyses used linear polynomials.

Five response surface models were determined, labelled A to E, each model using a different combination of parameters, as represented in Table 3, including traffic and the structural temperature of the suspension cable and deck. Cross et al. (2013) found a link between dynamic response and bridge heating and cooling rate, so the temperature difference between subsequent time series samples was included in the analyses. Finally broadband root mean square vertical deck accelerations were considered as a proxy for dynamic loads due to vehicles and a possible alternative to the imperfect methods previously described for estimating vehicle mass.

The correlation coefficients determined from these five analyses are represented as bars in Figure 15. For all five modes, the application of the traffic mass as the sole variable produces a better fit (B) than using all the temperature variables (C). Combining the traffic and temperature dependent parameters (D) provides an ideal model of the monitored frequencies, as anticipated.

The traffic mass determined by hourly traffic count provides a much better fit (B) than using the vertical deck accelerations alone (A). While the deck acceleration is related to traffic mass, the relationship involves vehicle weights, speeds and positions, parameters not simple to acquire or describe. The acceleration data also offered very little improvement to the match on all five modes (E), so they were neglected in further 
studies.

In order to assess roughly the relative importance of each of the four remaining components to the variation of each frequency, the input data were normalised to unit standard deviation. Thus the coefficients determined from fitting the models can be compared directly.

Figure 16 shows how much each variable contributes to the overall variation of each modal frequency. The pie graph for VS1 suggests predominant dependence on traffic mass. Mode VA1 is also mostly influenced by traffic, but temperature effects are now also significant. The largest contributor to the two observed lateral modes LS1a and LS1b is the suspension cable temperature. For TS1 on first appearance deck temperature controls the frequency, although the analysis has ignored the eccentricity of the traffic mass (related to polar moment of inertia about the longitudinal axis of the deck).

The combined effect of spatial and temporal variation of temperature on bridge dynamic and static response is the subject of a separate investigation (Westgate, 2012) and the remainder of this paper concentrates on finding a physical explanation for vehicle mass effect through finite element simulations.

\section{Physics-based investigation of effects of vehicle mass on bridge dynamics}

Most simulations of vehicle effects on bridges consider dynamic augmentation effects and/or interaction between the vehicle and the structure (Kwasniewski et al., 2006; González et al., 2008; Moghimi \& Ronagh, 2008). Relatively few have identified shifts in the bridge's natural frequencies, which are a result of the location and mass of the vehicles, as well as their suspension system (Li et al., 2003; Yang, 2004; Westgate et al., 2013). For long span bridges the effect of vehicle-bridge interaction has a negligible 
contribution, since the frequencies of the first few modes (up to $1 \mathrm{~Hz}$ ) are much lower than the range of dynamic forces excitation frequencies due to vehicle body-bounce modes $(2-5 \mathrm{~Hz})$. Hence the governing load condition on these structures is during a traffic jam, when the bridge is congested with traffic in an asymmetric load pattern and there is very little dynamic amplification on the static load.

\section{Finite Element model}

To aid interpretation of the bridge behaviour observed through the monitoring system, a finite element (FE) model of the bridge was developed (Westgate \& Brownjohn, 2010). The model was developed in ANSYS 12.1, with the truss members modelled with either BEAM4 or BEAM44 three dimensional elastic beam elements. Plate elements such as those found in the deck and the truss were modelled with SHELL63 elastic shell elements. All cables and hangers were modelled as LINK10 spar elements, with the "tension only" option selected so that they contributed zero stiffness to the structure when they were under compressive loads. The expansion gap for the bridge is located at the Saltash main tower, between the main span and Saltash side span. Any frictional stiffness caused by the bearings at the gap and the ends of the bridge was modelled as COMBIN14 linear spring elements.

Stay cable tensions (in the range $1.5 \mathrm{MN}$ to $3 \mathrm{MN}$ per cable) were estimated from long-term monitoring data. Since these data are not totally reliable, they were checked (and where appropriate replaced) via estimates from sample measurements of stay cable natural frequencies. The tensions in the suspension cable, however, cannot be retrieved by direct measurements since the monitoring system is a retrofit. Instead, the main suspension cable tensions (constant horizontal component $\mathrm{H}$, per cable) in the FE model were initially taken as $18.7 \mathrm{MN}$. This estimate was obtained starting from the value of 
$\mathrm{H} \cong 22 \mathrm{MN}$ for the 1961 configuration and using the parabolic catenary equation with the known weight density, span and sag $(34 \mathrm{~m})$ and accounting for the estimated 7.8MN total of vertical tension components for stay cables attached to the main span. Tensions were iterated until the deflections in the suspended structure and the main tower were as small as possible in the dead load condition; a methodology that is similar to actual suspension cable erection.

The FE model was calibrated manually to modal properties obtained from the ambient vibration survey for mode shapes and subsequent monitoring (Brownjohn et al., 2008) for mean frequenies, with the aim that the model would be better at reproducing the dynamic behaviour of the actual structure. The calibration process involved slightly modifying the values that represent the stiffness and density of the deck, truss and cantilevered lanes, as well as the suspension and stay cables.

The calibration process is multi-faceted and did not lend itself to formal automation. Part of the problem is the form-finding exercise where initial tensions in main and stay cables have to be adjusted to develop the neutral dead load configuration with as-built deflections in the suspended structure and the tower (Westgate \& Brownjohn, 2010); the complex tension stiffening arrangement meant that modifying the tension in one cable affects the tension in the other cables with limited and/or unreliable cable tension data to provide reference points. Tamar Bridge has some similarities with Roebling Bridge that carries $10 \%$ of total bridge load in the stays (Ren et al., 2004) and there are similar difficulties in identifying the in-operation tensions. For Tamar Bridge, above $1 \mathrm{~Hz}$ the truss stiffness dominates the modal properties with tension stiffening making a significant contribution only to the lowest few modes. The tension stiffening contribution from the stays has negligible effect on all but the first two vertical modes - the stay cable tensions are influenced by dynamic behaviour 
instead of the reverse.

Good agreement can sometimes be achieved by good modelling aided by automated model updating, but it usually works best with simple non-redundant structures, and the improvements here are marginal. In fact, Tamar Bridge has so far presented a challenging case study for model calibration, lending support to the view that no single model provides a perfect representation of a structure when matched to provided experimental data (Goulet et al., 2012). The imperfect model used here is one that the authors believe provides the best match to the relevant modes.

\section{Representing vehicle traffic in the FE model}

Due to the low bridge frequencies compared to the vehicle modes it is reasonable to treat each vehicle as a rigid mass and to consider the quasi-static vehicle weight (and consequent effect on cable tensions), with the reaction forces due to passage over the uneven surface appearing as a broadband force exciting all bridge modes.

The masses were applied in the FE model as multiples of 1660kg rigid two-axle vehicles on the structure. Each vehicle was modelled as having half its mass over each axle, and the vehicle density was incremented in successive runs of the FE model as shown in Figure 17, assuming an even distribution of vehicles. To consider the effects of asymmetric mass distribution, the same analyses were performed with the vehicles shifted one lane, as shown in Figure 18, with one line of traffic situated on the cantilevered deck.

\section{Linking changes in modal properties to variation in traffic mass}

\section{Variation of deck mode natural frequencies}

Even compared to the $3190 \times 10^{3} \mathrm{~kg}$ mass of the suspended structure the gross mass of 
traffic is relatively small. For the heaviest traffic jam observed, traffic was estimated at around $160 \times 10^{3} \mathrm{~kg}$ using webcam images. However, such events are rare and provide a clear anomaly in the frequency time series. Hence for free flowing traffic the modelling aims to check that the simulations reproduce observed traffic effects such as the clear morning frequency drop of Figure 4.

The surface fitting aimed only to provide qualitative indication of the contribution of traffic load to frequency variation. To provide quantitative estimates, frequencies were linearly regressed against vehicle mass using data filtered to include only samples corresponding to low winds and a $5^{\circ} \mathrm{C}$ range of cable temperatures, shown in Figure 19. The fitting corroborates the surface fit results. Even though mode LS1a displays the clearest correlation with temperature it also has the strongest effect of traffic mass, at $0.032 \%$ per $10^{3} \mathrm{~kg}$. Small wonder this mode displays such a huge range of frequencies with a large negative statistical skew.

Mode VS1 and VA1 frequencies both vary by $0.014 \%$ and $0.016 \%$ per $10^{3} \mathrm{~kg}$ respectively, although the frequency of mode VA1 is almost twice that of VS1, so its variation is much more obvious within the time series. $37 \%$ of the sampled frequencies for TS1 lie within $0.5 \%$ of the bridge frequency with no applied mass, which is why there is no obvious trend in the results unless a line of "best fit" overlays the data. However, $80 \%$ of the samples lie below the origin of the y axis, due to the high skew for this mode (Table 2). Since the reduction in the response seems to be unrelated to the scale of the vehicle load, eccentricity (lane occupancy) of the loading might be the cause of this behaviour.

For symmetric distribution of traffic in the centre lanes, the FE model results in Figure 20 show a clear inverse linear relationship between traffic mass and modal frequency for the vertical modes. The simulated frequency reductions for VS1 and VA1 
are approximately half the changes observed experimentally. For mode LS1a the simulations indicate a modest increase of frequency since the increased main cable tension more than compensates for the increase in mass. The drop in the frequency change can be replicated only if the main cable tension change due to increased dead load is ignored, as shown by points marked as "LS1a (no tens)".

For TS1, with vehicles located in the three northern lanes as would be the case for morning rush hour traffic (commuter traffic from Saltash uses the northern cantilever), Figure 21 shows frequency reduction consistent with the monitoring reduction on account of the mass eccentricity. The hourly arranged time series for mode TS1 in Figure 22 show a distinct trough in frequencies between 06:00 and 09:00, corroborating the eccentric load simulation.

Table 4 summarises the simulations and linear single-variable fitting and shows that observed frequency changes are on average three times greater than those predicted even though (excepting LS1a with cable tension changes) the tendencies have been simulated. This shows that even with reasonable agreement of experimental and analytical finite element models, there can be significant limitations in capability for scenario simulation. With its complex boundary conditions, cantilever lanes and cable redundancy the Tamar Bridge is an extreme case to test the feasibility of scenario simulation for SHM using physics-based models.

\section{Summary and conclusions}

Both the modal property data collected by the long-term monitoring system and the simulations indicate that the dynamic properties of the Tamar Bridge change depending on levels and spatial distribution of vehicular traffic. It is also noted that role of traffic mass in the frequency variation differs from mode to mode, and that structural 
temperatures have a smaller influence in most of the modes considered. It is important that such changes are understood and corrected for if conclusions about structural condition are to be inferred from changes in modal properties. This paper has presented a physics-based approach to explaining these effects by attempting to reproduce them.

While the FE model has been able to regenerate observed modal properties it has not been able to replicate the frequency variations equally well for all modes, with the first lateral mode defying attempts to replicate its behaviour unless expected cable tension changes are ignored. A more accurate prediction might be possible with better knowledge of actual vehicle weight and trajectory, and some assistance could be provided from Weigh in Motion data or other means of accurately recording vehicle mass.

\section{Acknowledgements}

The research was supported by both EPSRC and EU Framework 7 funding. Authors would like to acknowledge the strong support of David List and Richard Cole from Tamar Bridge and the contribution of Peter Carden who developed the original automated modal parameter identification system. Also thanks to Chris Jones for Figure 2. 


\section{References}

Au, S. K. (2012). Connecting Bayesian and frequentist quantification of parameter uncertainty in system identification. Mechanical Systems and Signal Processing, 29, 328-342.

Brownjohn, J. M. W. (2007). Structural health monitoring of civil infrastructure. Philosophical Transactions of the Royal Society of London, Series A, Mathematical and Physical Sciences.

Brownjohn, J. M. W. \& Carden, P. (2008). Real-time operation modal analysis of Tamar Bridge. Proceedings, IMAC XXVI (pp. 1-8). Orlando, Florida, USA.

Brownjohn, J. M. W., de Stefano, A., Xu, Y.-L., Wenzel, H. \& Aktan, A. E. (2011). Vibrationbased monitoring of civil infrastructure: challenges and successes. Journal of Civil Structural Health Monitoring, 1(3-4), 79-95.

Brownjohn, J. M. W., Pavic, A., Carden, E. P. \& Middleton, C. J. (2007). Modal testing of Tamar suspension bridge. Proceedings, IMAC XX. Orlando, Florida, USA.

Cross, E., Koo, K. Y., Brownjohn, J. M. W. \& Worden, K. (2013). Long-term monitoring and data analysis of the Tamar Bridge. Mechanical Systems and Signal Processing, 35(1-2), $16-34$.

Department for Transport. (2008). Road Statistics 2007: Traffic, Speeds and Congestion (pp. 178). London, UK.

Diana, G., Cheli, F., Zasso, A., Collina, A. \& Brownjohn, J. M. W. (1992). Suspension bridge parameter identification in full-scale test. Journal of Wind Engineering and Industrial Aerodynamics, 41, 165-176.

Ding, Y.-L. \& Li, A. (2011). Temperature-induced variations of measured modal frequencies of steel box girder for a long-span suspension bridge. International Journal of Steel Structures, 11(2), 145-155.

Farrar, C. R. \& James III, G. H. (1997). System Identification From Ambient Vibration Measurements On A Bridge. Journal of Sound and Vibration, 205(1), 1-18. 
González, A., Rattigan, P., O’Brien, E. J. \& Caprani, C. (2008). Determination of bridge lifetime dynamic amplification factor using finite element analysis of critical loading scenarios. Engineering Structures, 30(9), 2330-2337.

Goulet, J.-A., Kripakaran, P. \& Smith, I. F. C. (2010). Multimodel Structural Performance Monitoring. Journal of Structural Engineering, 136(10), 1309-1318.

Koo, K. Y., Brownjohn, J. M. W., List, D. I. \& Cole, R. (2012). Structural health monitoring of the Tamar suspension bridge. Structural Control and Health Monitoring, 20(4), 609-625.

Kwasniewski, L., Li, H., Wekezer, J. \& Malachowski, J. (2006). Finite element analysis of vehicle-bridge interaction. Finite Elements in Analysis and Design, 42(11), 950-959.

Li, J., Su, M. \& Fan, L. C. (2003). Natural Frequency of Railway Girder Bridges under Vehicle Loads. Journal of Bridge Engineering, 8(4), 199-203.

Magalhães, F., Cunha, A. \& Caetano, E. (2012). Vibration based structural health monitoring of an arch bridge: From automated OMA to damage detection. Mechanical Systems and Signal Processing, 28, 212-228.

Miao, C.-Q., Chen, L., C. \& Feng, Z.-X. (2011). Research on correlation of modal frequency of long-span bridge structures and environmental temperature. Proceedings, 2011 International Conference on Multimedia Technology (pp. 1175-1179). IEEE.

Moghimi, H. \& Ronagh, H. R. (2008). Development of a numerical model for bridge-vehicle interaction and human response to traffic-induced vibration. Engineering Structures, 30(12), 3808-3819.

Oh, C. K., Sohn, H. \& Bae, I.-H. (2009). Statistical novelty detection within the Yeongjong suspension bridge under environmental and operational variations. Smart Materials and Structures, 18(12), 125022.

Peeters, B. \& De Roeck, G. (1999). Reference-based stochastic subspace identification for output-only modal analysis. Mechanical System \& Signal Processing, 13(6), 855-878.

Pytharouli, S. I. \& Stiros, S. C. (2008). Spectral analysis of unevenly spaced or discontinuous data using the "normperiod" code. Computers \& Structures, 86(1-2), 190-196. 
Ren, W.-X., Blandford, G. E. \& Harik, E. H. (2004). Roebling Suspension Bridge. 1: Finiteelement model and free vibration response. Journal of Bridge Engineering, 9(2), 110-118.

Sadik-Khan, J. (2012). New York City Bridge Traffic Volumes 2010. New York.

Sohn, H. (2007). Effects of environmental and operational variability on structural health monitoring. Philosophical transactions. Series A, Mathematical, physical, and engineering sciences, 365(1851), 539-60.

Van Overschee, P. \& De Moor, B. (1996). Subspace identification for linear systems. Kluwer Academic Publishers.

Westgate, R. J. (2012). Environmental Effects on a Suspension Bridge's Performance. $\mathrm{PhD}$ thesis, University of Sheffield.

Westgate, R. J. \& Brownjohn, J. M. W. (2010). Development of a Tamar Bridge Finite Element Model. Proceedings, IMAC XXVIII. Jacksonville, Florida.

Westgate, R. J., Koo, K.-Y., Brownjohn, J. M. W. \& List, D. (2013). Suspension bridge response due to extreme vehicle loads. Structure and Infrastructure Engineering, 1-13. DOI:10.1080/15732479.2013.767844

Wyatt, T. A. (1992). Bridge Aerodynamics 50 Years After Tacoma Narrows - Part I: The Tacoma Narrows Failure And After. Journal of Wind Engineering and Industrial Aerodynamics, 40(3), 317-326.

Xia, Y., Chen, B., Weng, S., Ni, Y. Q. \& Xu, Y. L. (2012). Temperature effect on vibration properties of civil structures: a literature review and case studies. Journal of Civil Structural Health Monitoring, 2(1), 29-46.

Yang, Y.-B. (2004). Extracting bridge frequencies from the dynamic response of a passing vehicle. Journal of Sound and Vibration, 272(3-5), 471-493.

Zhang, Q. W., Fan, L. C. \& Yuan, W. C. (2002). Traffic-induced variability in dynamic properties of cable-stayed bridge. Earthquake Engineering \& Structural Dynamics, 31(11), 2015-2021. 
Table 1: Vehicle classification and proportion of traffic on Tamar Bridge.

Table 2: Statistical properties of the monitored modal frequencies.

Table 3: Variables used in response surface models.

Table 4: Relationship of reported frequencies to applied traffic mass.

Figure 1: Sensor placement on Tamar Bridge.

Figure 2: Cross-section of truss and deck (shear boxes not shown).

Figure 3: Temperature time series.

Figure 4: Mean mass of traffic per hour. Left: Mid-week traffic. Right: Weekend traffic.

Figure 5: Hourly traffic mass time series.

Figure 6: Mass on bridge during 15 daily periods. Top: Total mass on bridge. Bottom: Approximate mass upon the bridge.

Figure 7: Frequency time series.

Figure 8: Diurnal variation frequencies for VS1.

Figure 9: Diurnal variation frequencies for LS1a.

Figure 10: Diurnal variation frequencies for VA1.

Figure 11: Lomb-Scargle periodogram for VS1 frequencies.

Figure 12: Lomb-Scargle periodogram for LS1a frequencies.

Figure 13: Lomb-Scargle periodogram for VA1 frequencies.

Figure 14: Frequency vs. temperature; results collected at 04:00AM.

Figure 15: Correlation of the first five monitored frequencies to various response surface model predictions.

Figure 16: Significance of observed parameters in observed variation of bridge frequencies.

Figure 17: Distribution of 3, 6, 9 and 120 vehicles, along the central lanes.

Figure 28: Distribution of 3, 6, 9 and 120 vehicles, along the northern lanes.

Figure 19: Monitored frequency change vs. traffic mass.

Figure 20: FE simulated frequency change vs. traffic mass, vehicles in centre lanes.

Figure 21: FE simulated frequency change vs. traffic mass, vehicles in northern lanes.

Figure 22: Diurnal variation frequencies for TS1. 


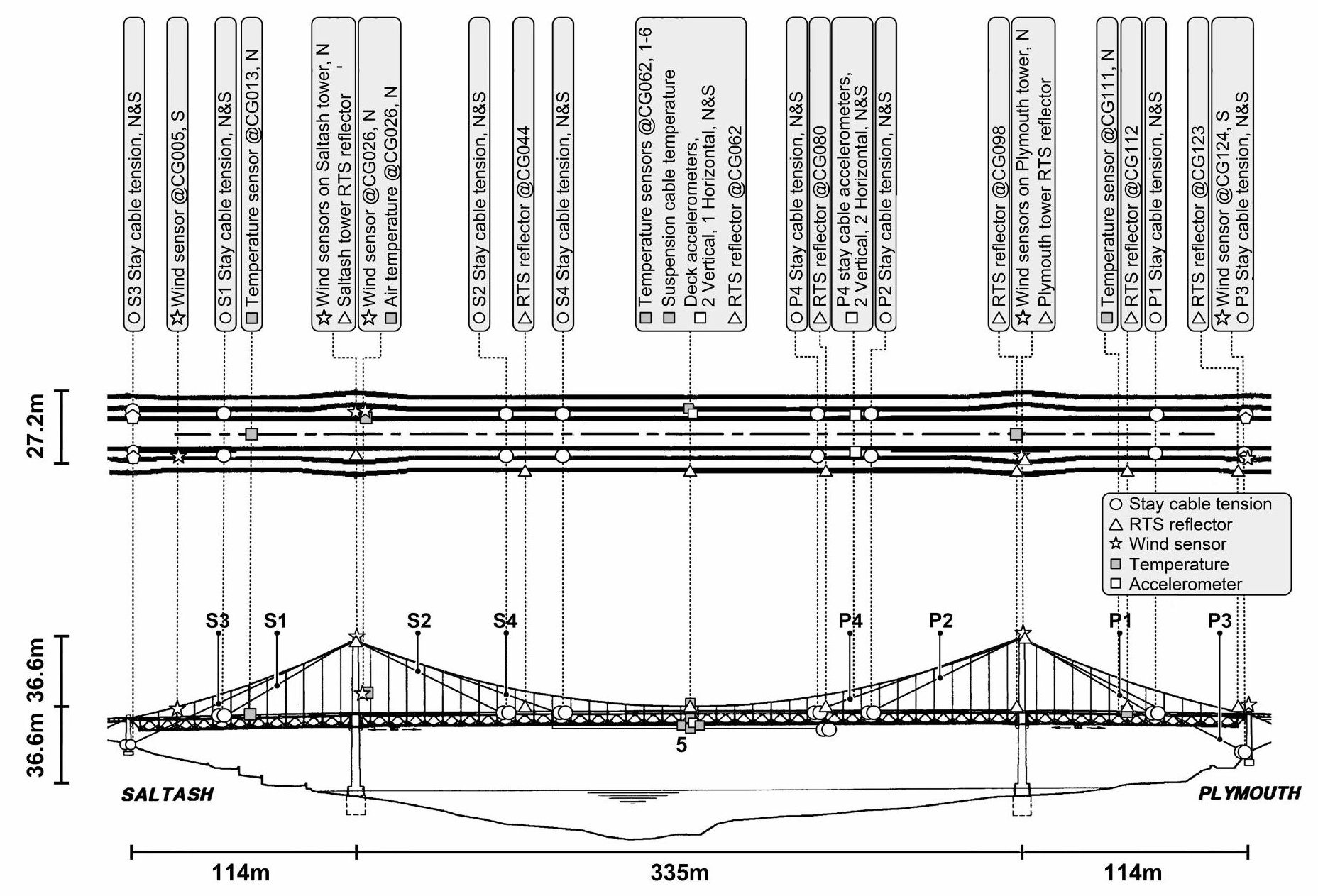




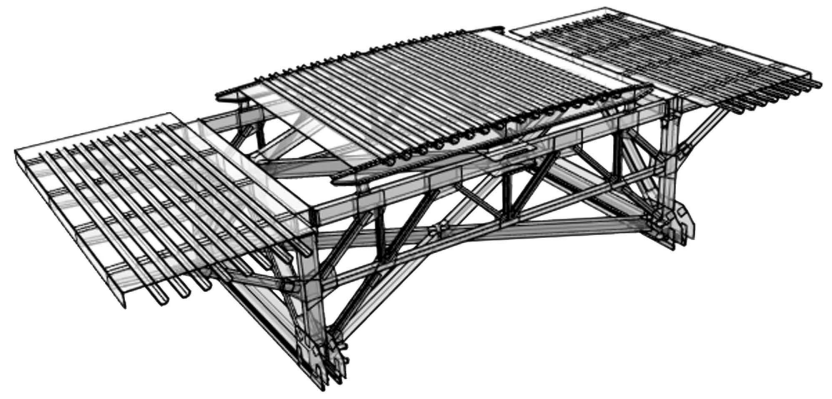




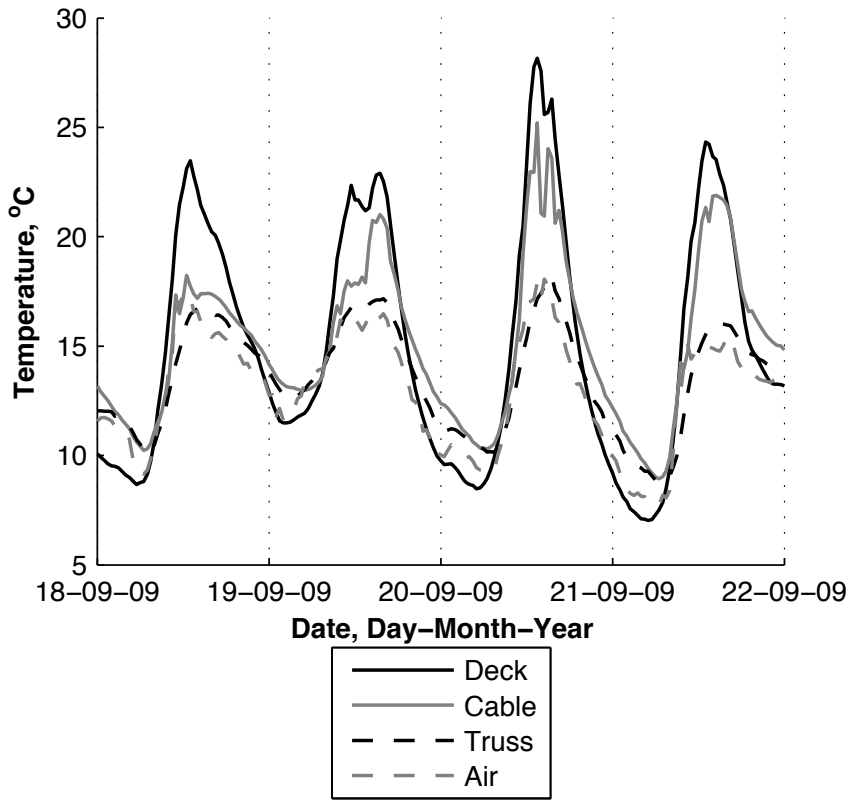


Hourly mass, kg
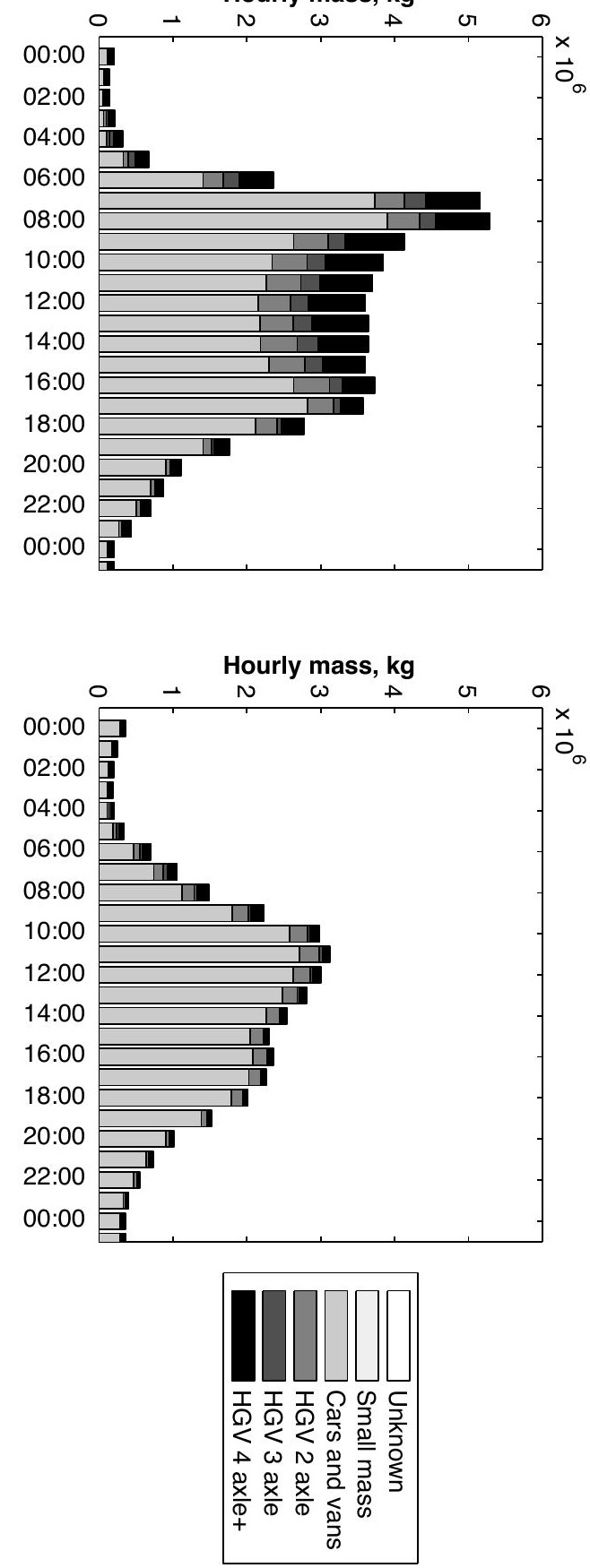

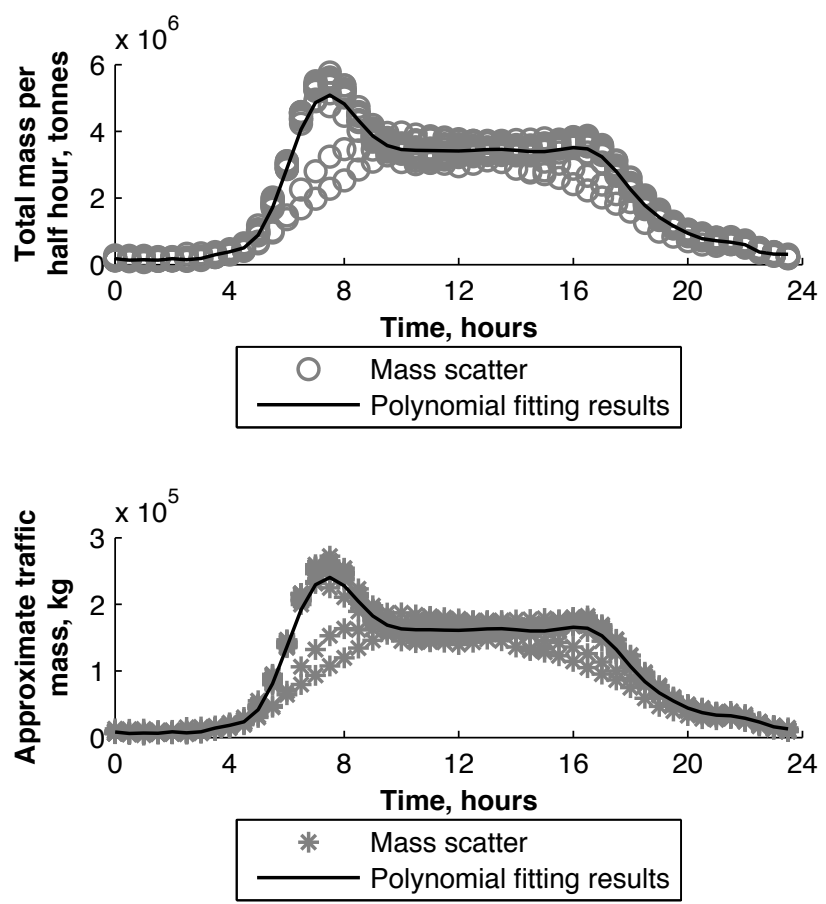


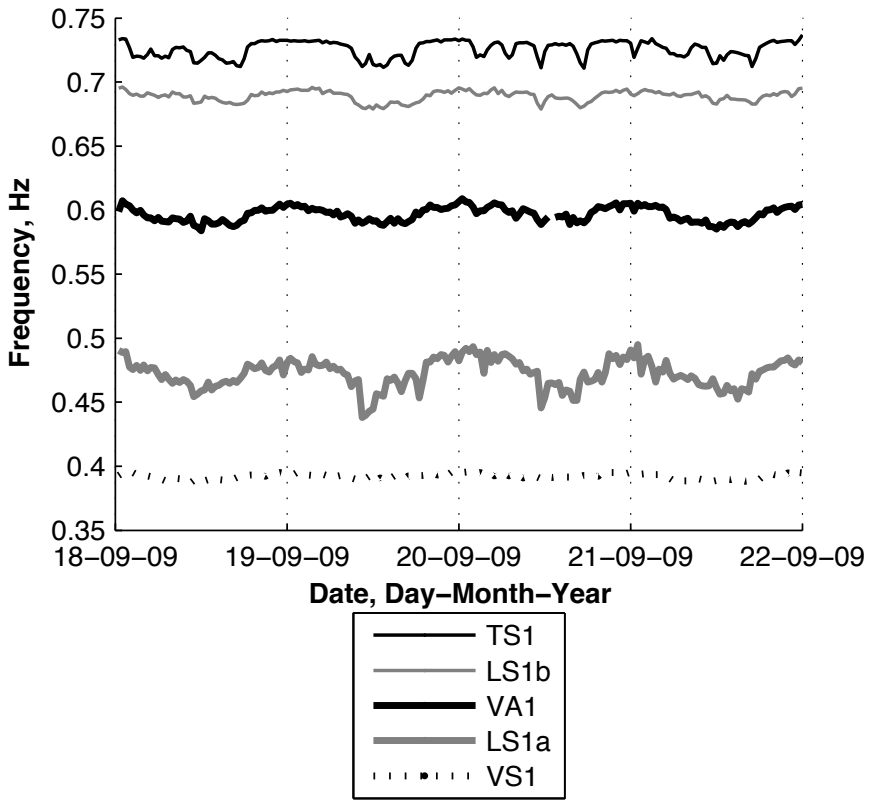



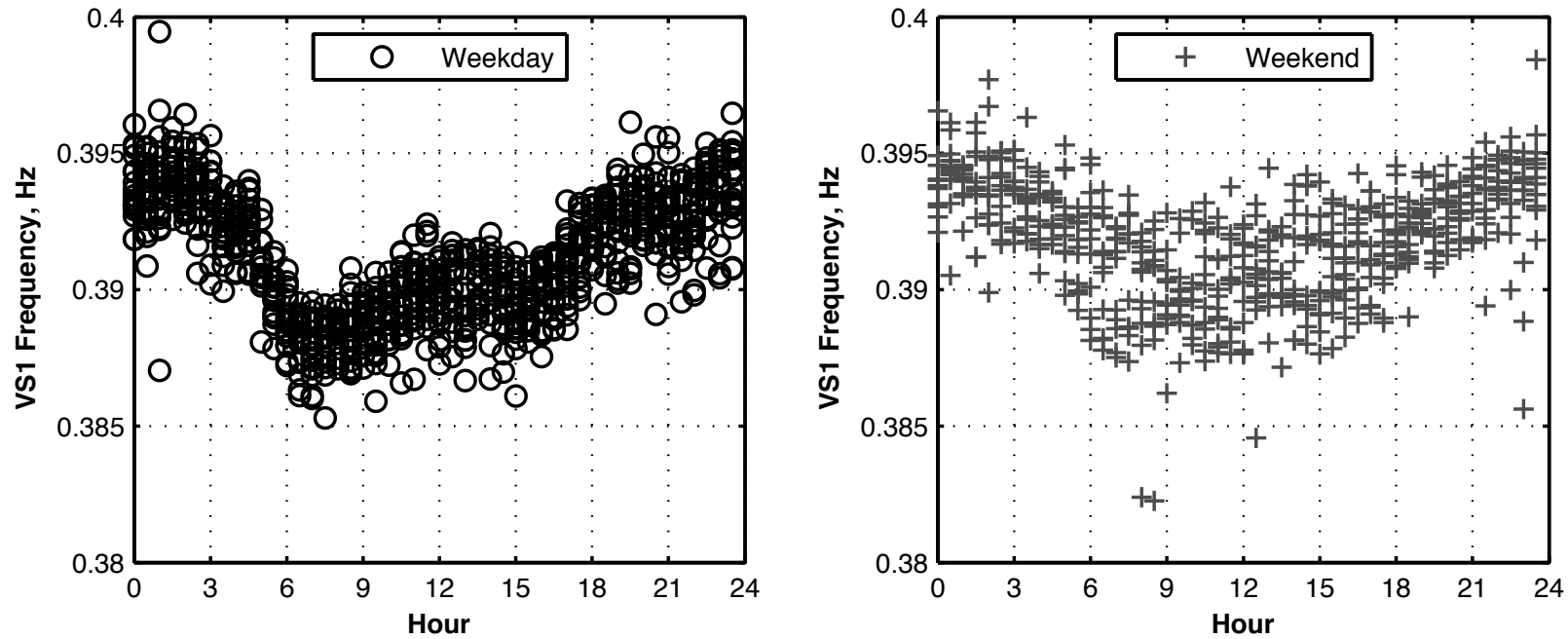

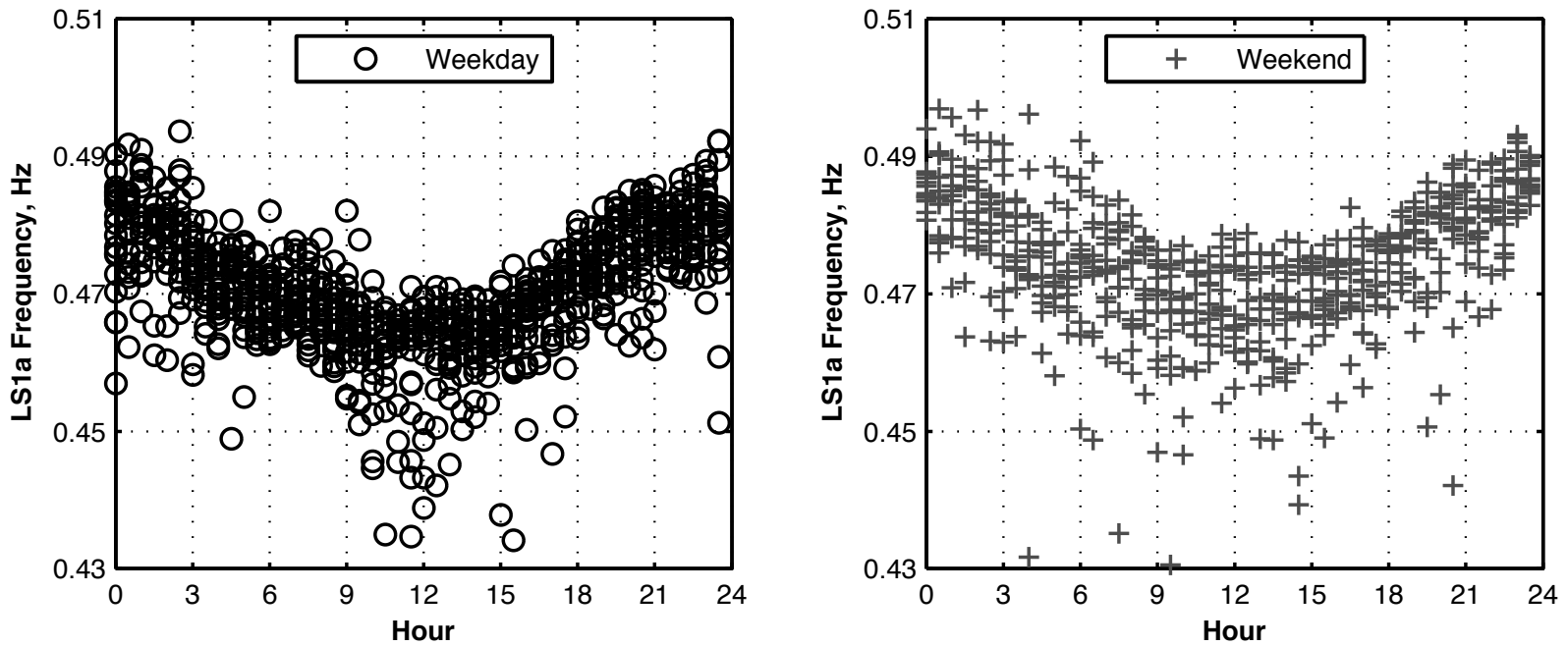

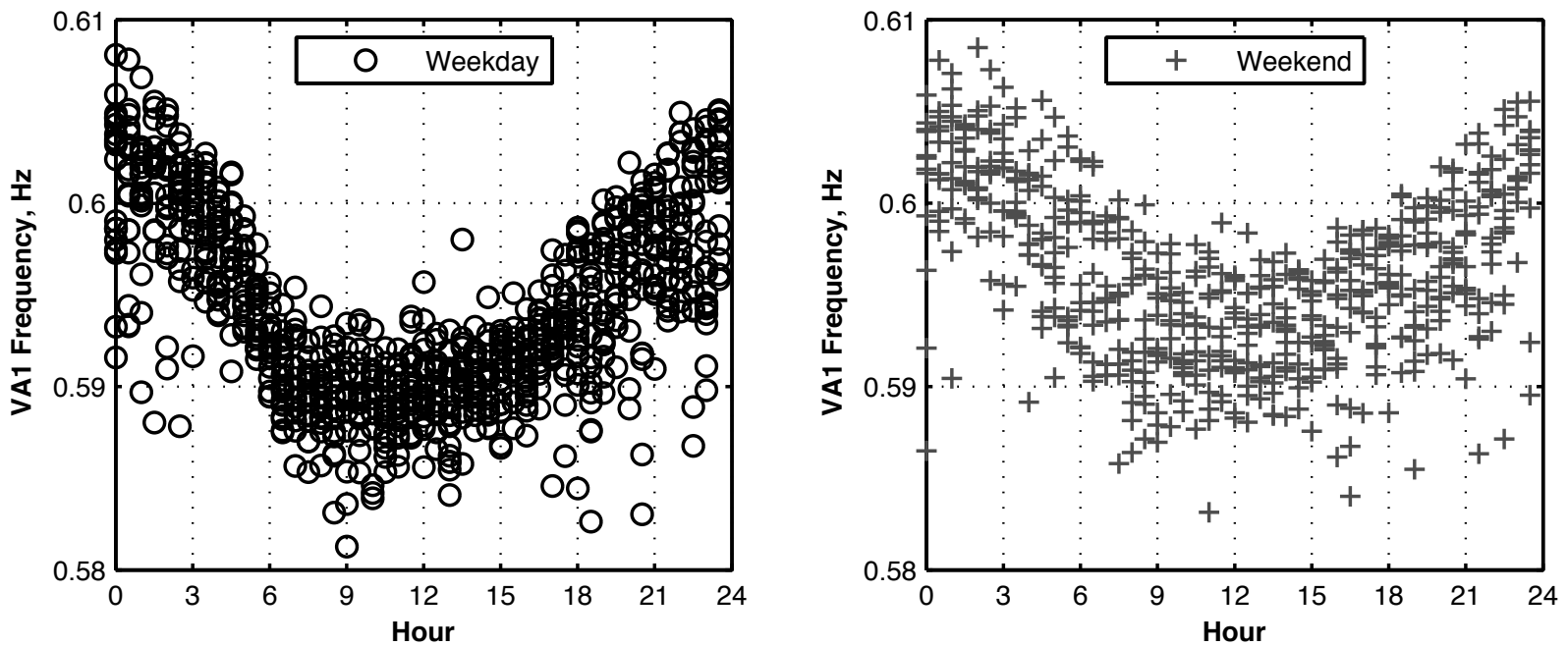

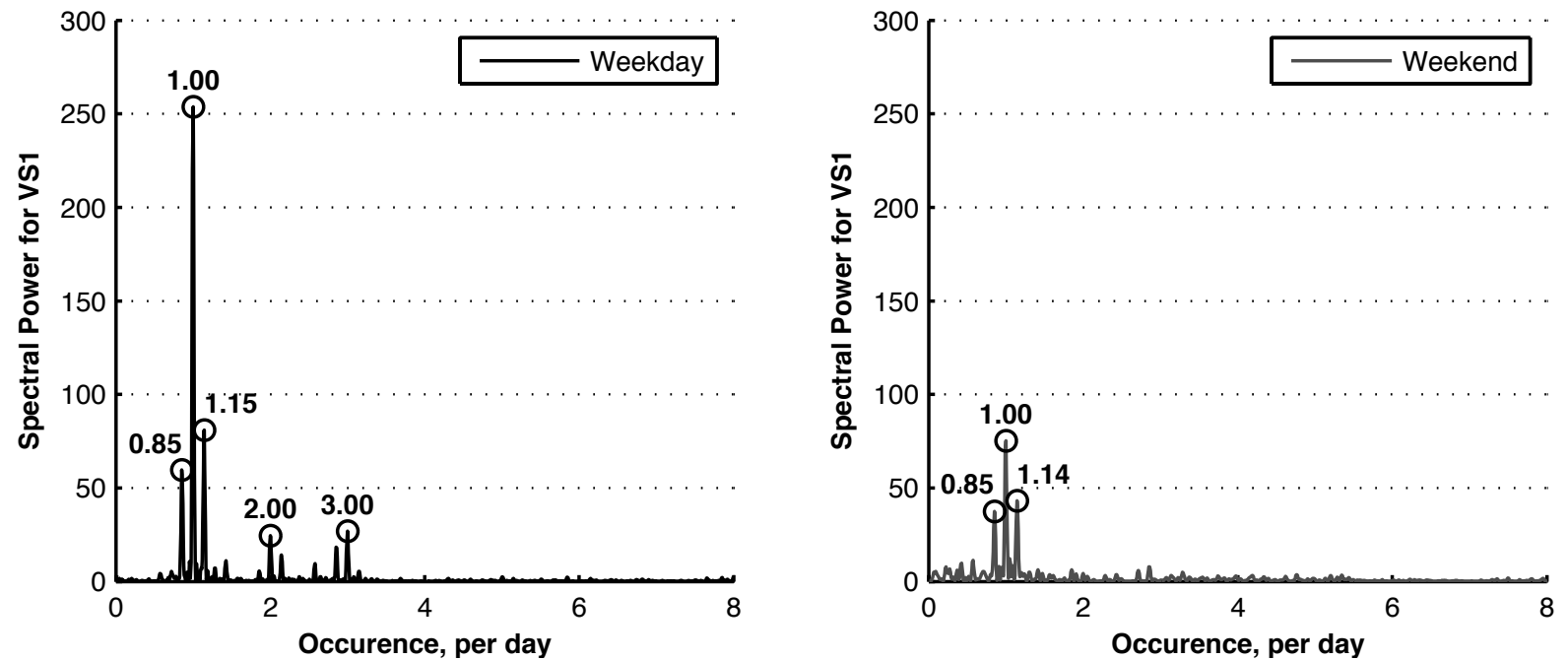

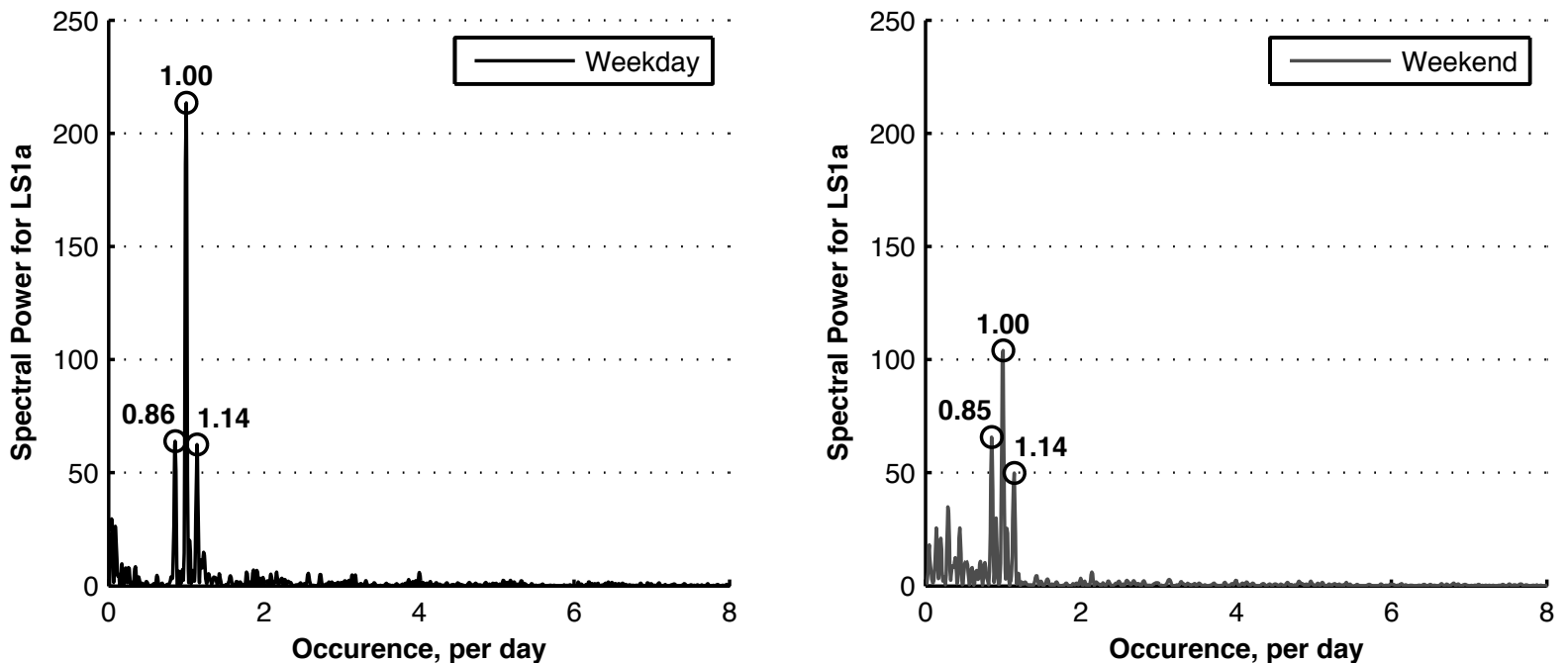

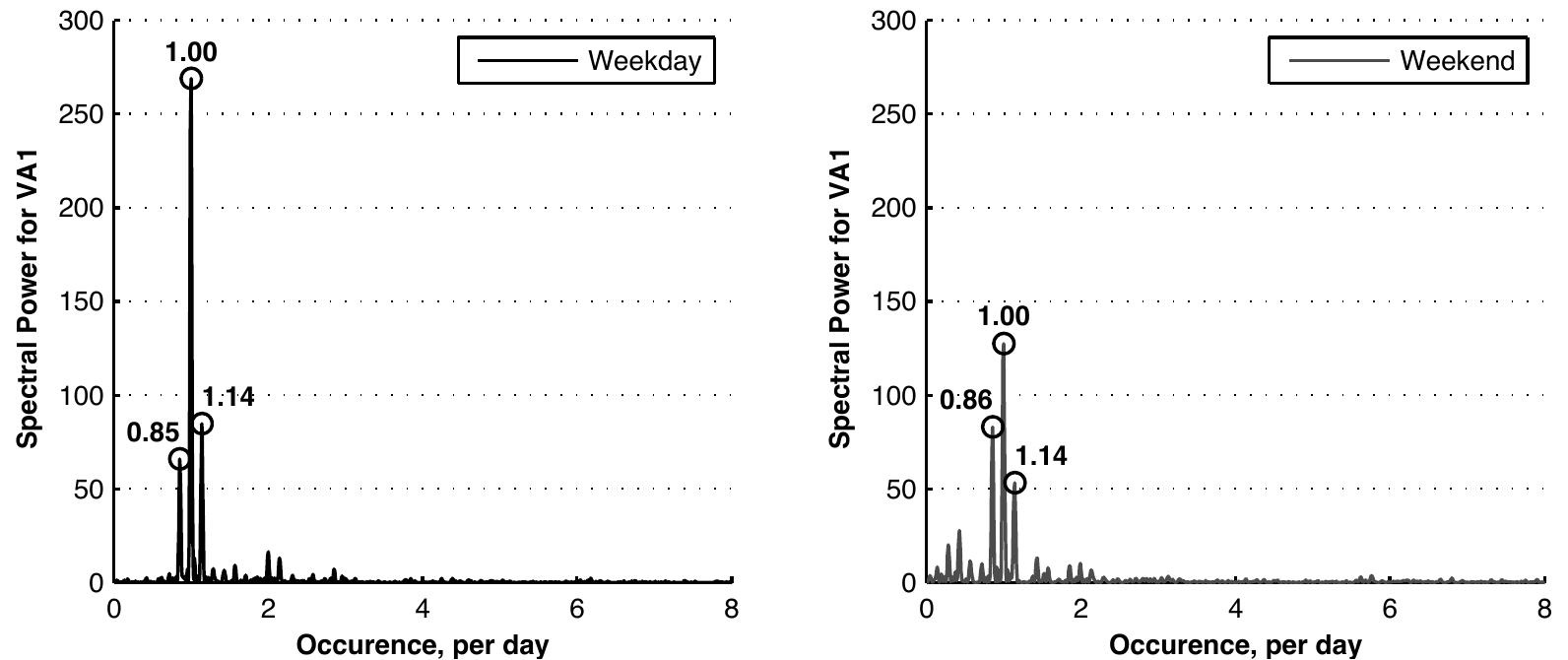


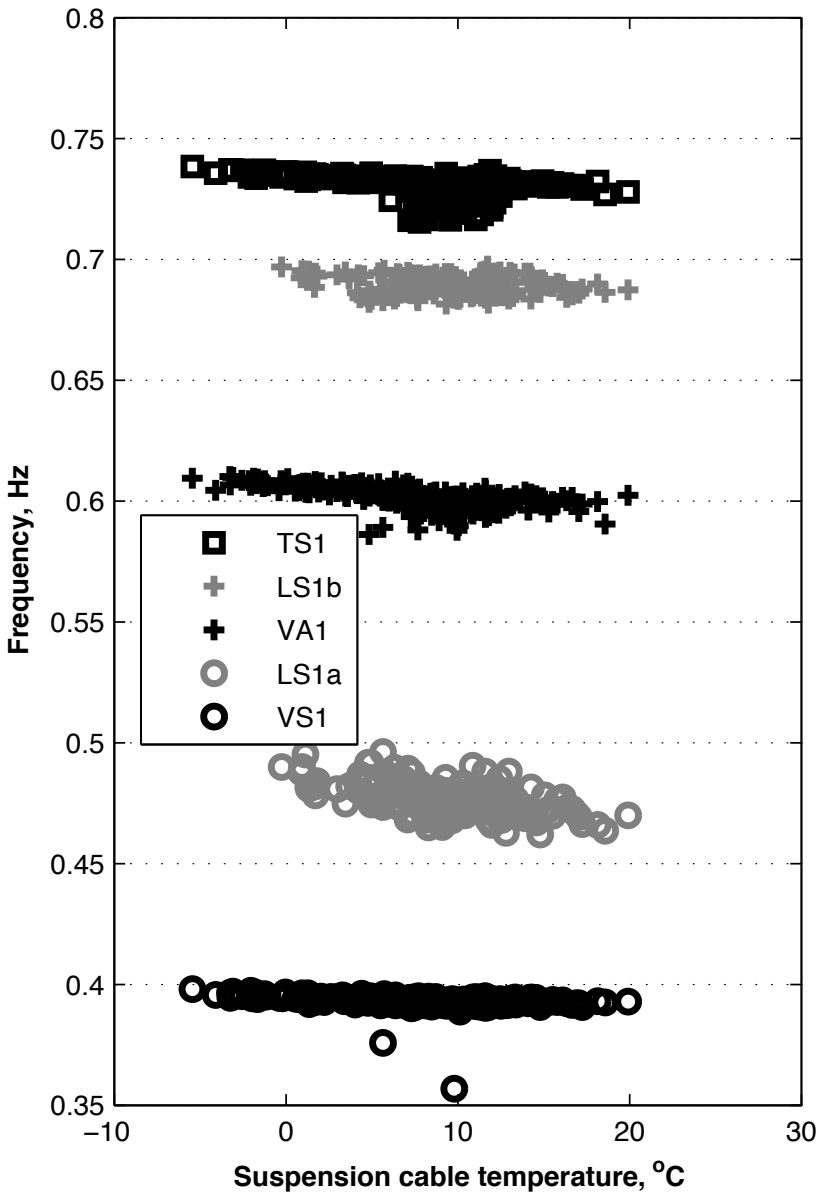


VS1

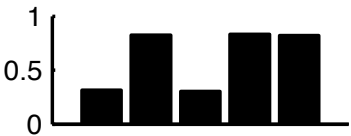

A B C D E VA1

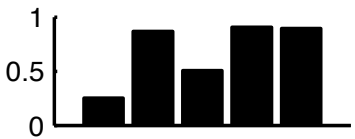

A B C D $E$ TS1

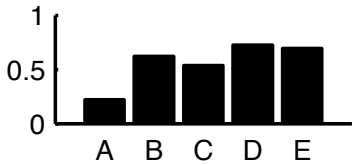

LS1a

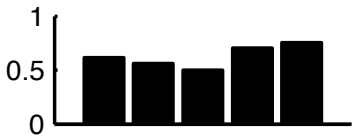

A B C D E LS1b

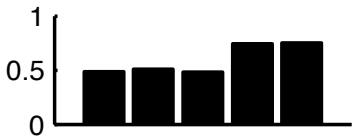

A B C D E 

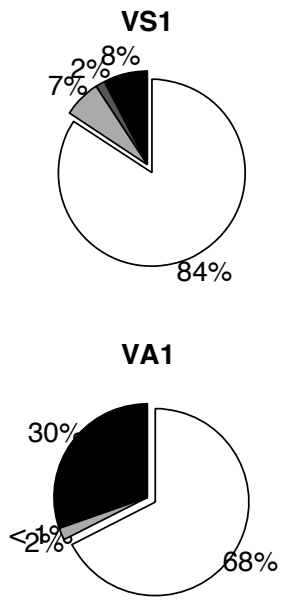

TS1

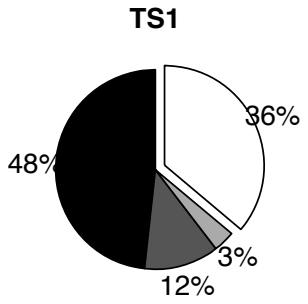

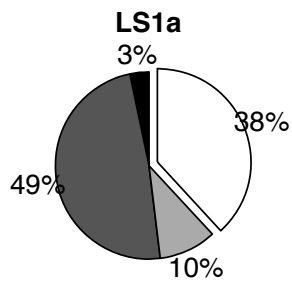

LS1b

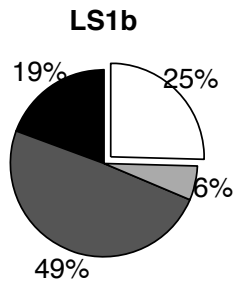

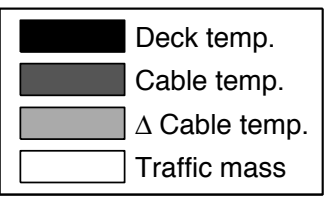




\section{KEY}

$\infty$ One $1660 \mathrm{~kg}$ vehicle

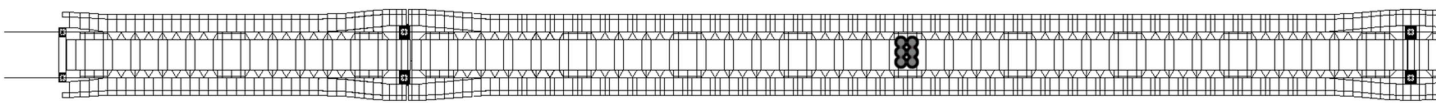

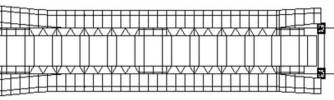

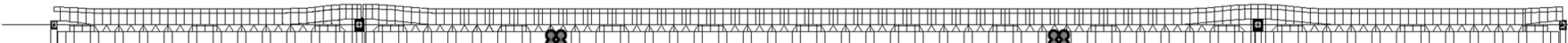

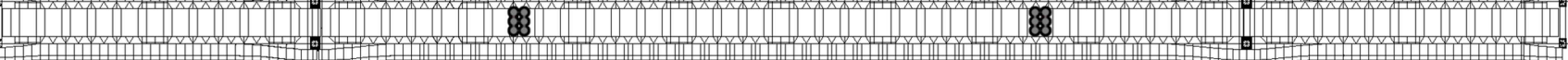

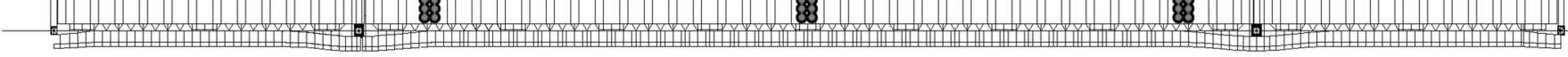




\section{KEY \\ $\infty$ One $1660 \mathrm{~kg}$ vehicle}

:

88 m n

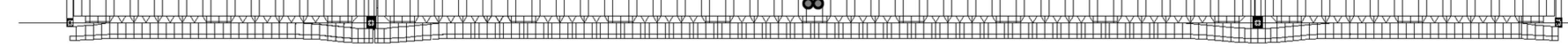

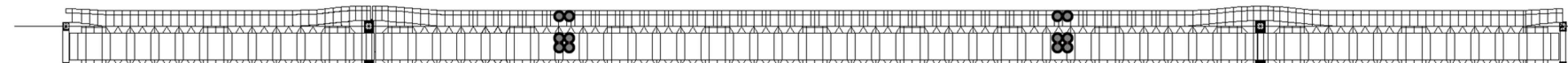

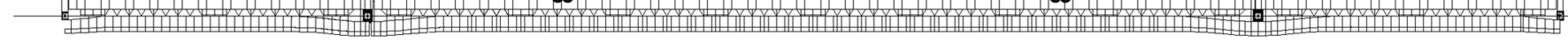

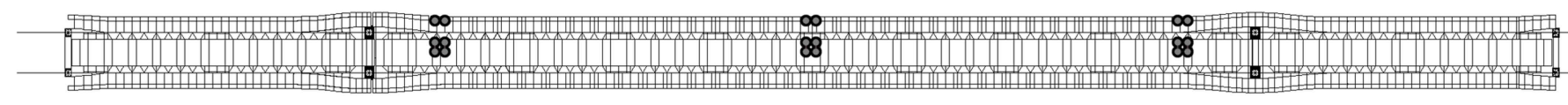



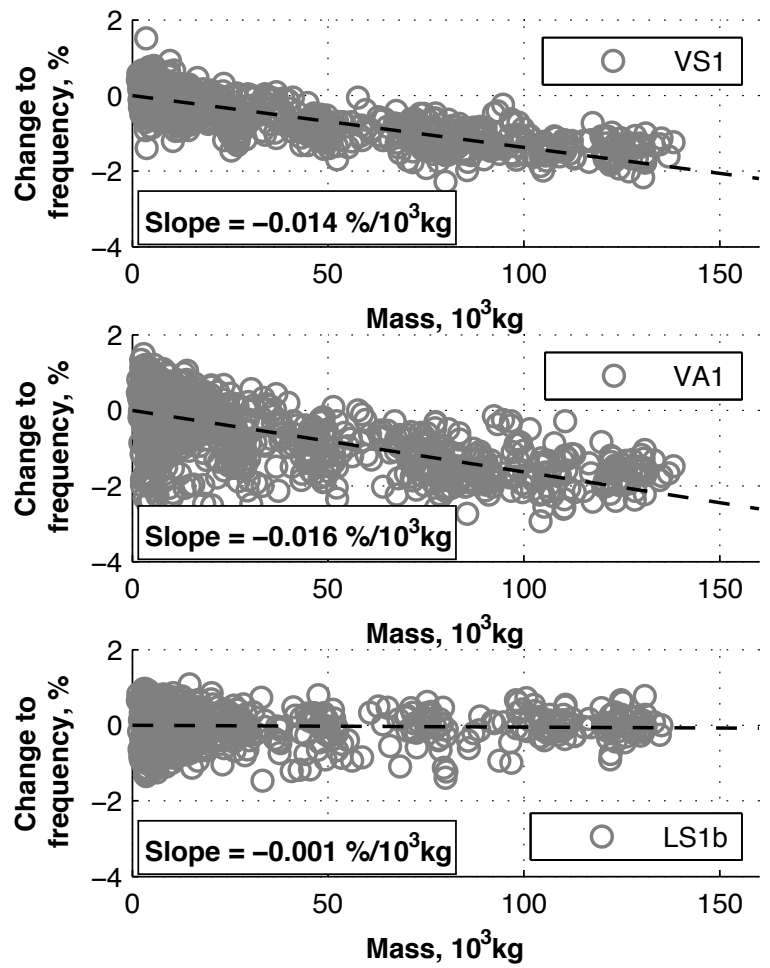
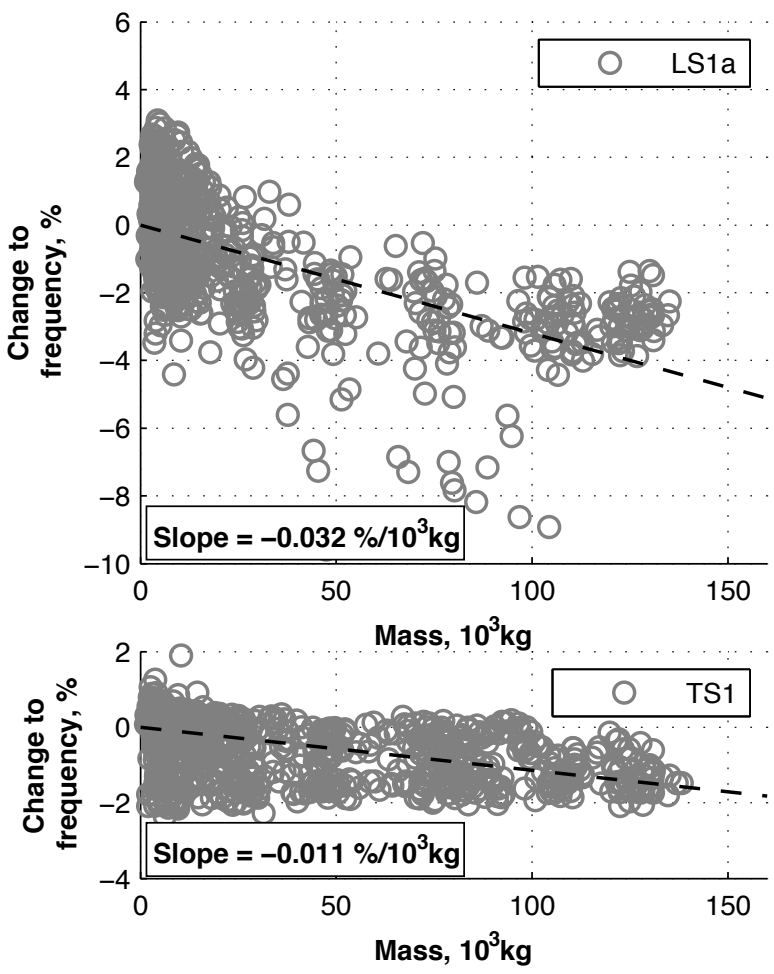


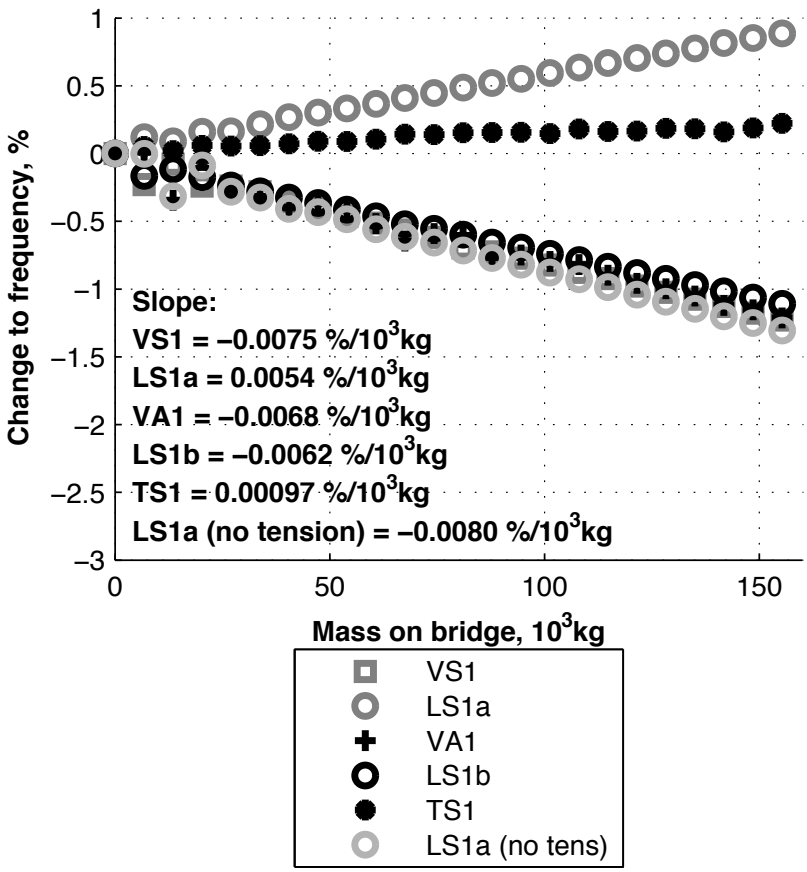




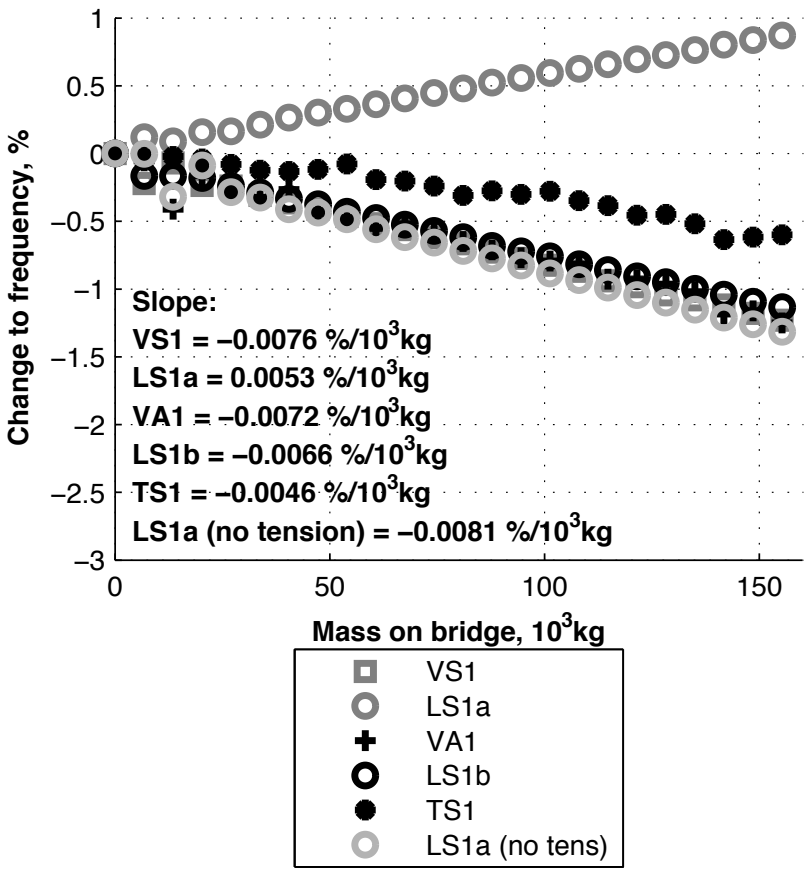



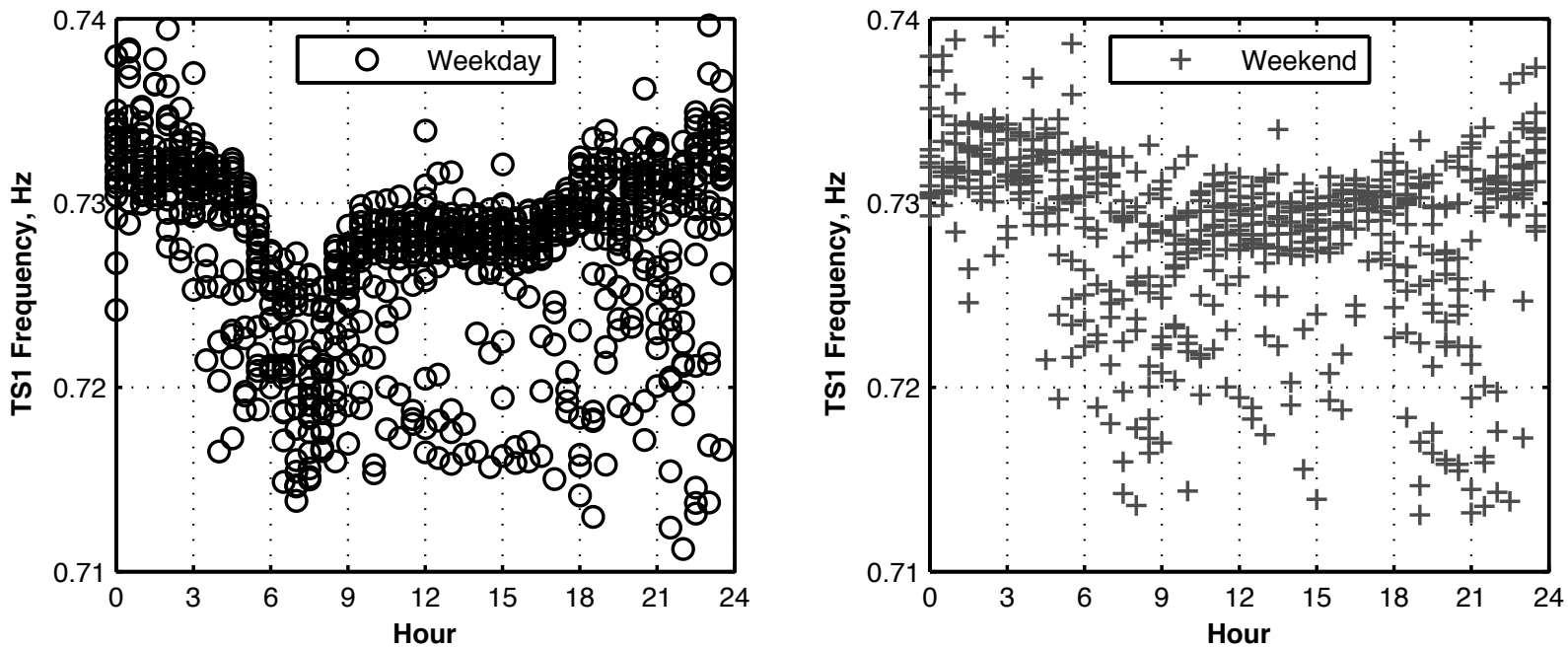
Table 1: Vehicle classification and proportion of traffic on Tamar Bridge.

\begin{tabular}{|c|c|c|c|}
\hline & & Average gross vehicle & $\%$ of monitored \\
\hline CLASS00 & Unknown & $\mathrm{N} / \mathrm{A}$ & 0.01 \\
\hline CLASS01 & Motorcycles, etc. & $0^{*}$ & 1.75 \\
\hline & Cars & $\begin{array}{l}(0.856 \times) \\
1500\end{array}$ & \\
\hline CLASS02, CLASS06 & Vans & $\begin{array}{l}(0.144 \times) \\
2600\end{array}$ & 93.48 \\
\hline CLASS03, CLASS07 & Two axle HGV** & 6800 & 2.83 \\
\hline CLASS04, CLASS08 & Three axle $\mathrm{HGV}^{* *}$ & 17400 & 0.56 \\
\hline CLASS05, CLASS09 & $\begin{array}{l}\text { Four (or more) axle } \\
\mathrm{HGV}^{* *}\end{array}$ & 22800 & 1.37 \\
\hline
\end{tabular}

* Unknown average mass; treated as having negligible contribution to total mass of traffic.

** HGV: Heavy Goods Vehicles 
Table 2: Statistical properties of the monitored modal frequencies.

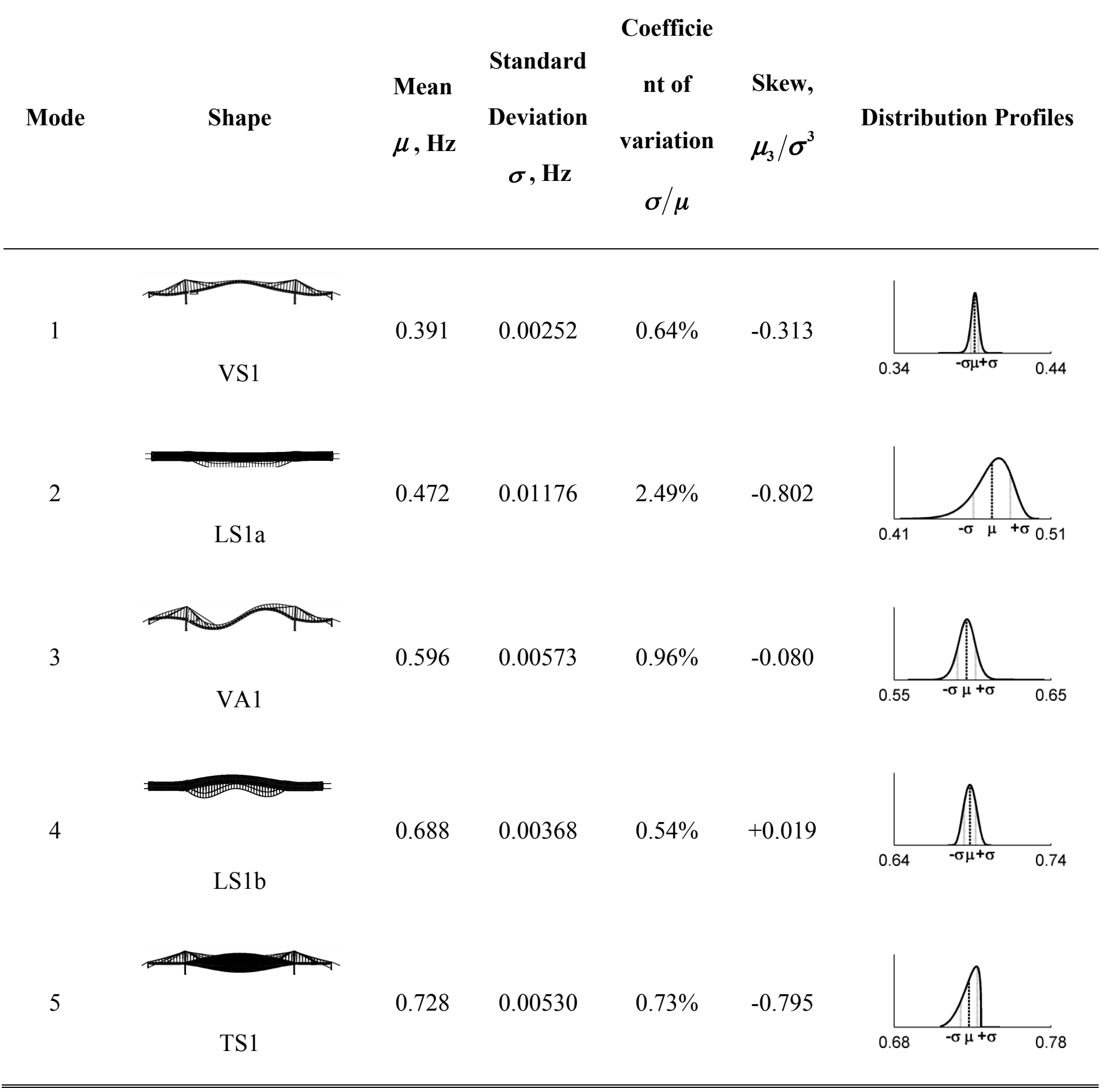

where ${ }^{\mu_{3}}$ is the third moment about the mean. 
Table 3: Variables used in response surface models.

Analysis Variables

Temperature

Deck
$\Delta$ Sup.

cable temp.

Sup. cable

A

B

C

D

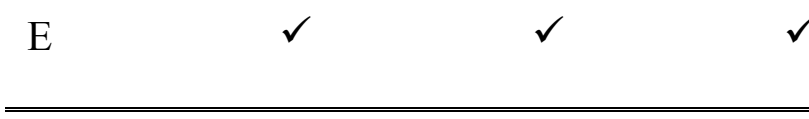

Traffic mass

Vertical

deck accel. $\checkmark$

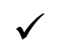

$\checkmark$ $\checkmark$

$\checkmark$

$\checkmark$<smiles>[AlH2]</smiles> 